\title{
VIAXES LITERARIAS E CULTURAIS ENTRE GALICIA E AUSTRALIA ${ }^{1}$ \\ María Jesús Lorenzo Modia \\ Universidade da Coruña
}

1 Esta investigación foi completada grazas á axuda do Programa de Consolidación concedida pola Xunta de Galicia a través da Rede de Lingua e Literatura Galega e Identidade II R2014/043, e ao proxecto de investigación do Ministerio de Economía e Competitividade (FFI2012-35872), que por este medio se agradecen expresamente. 


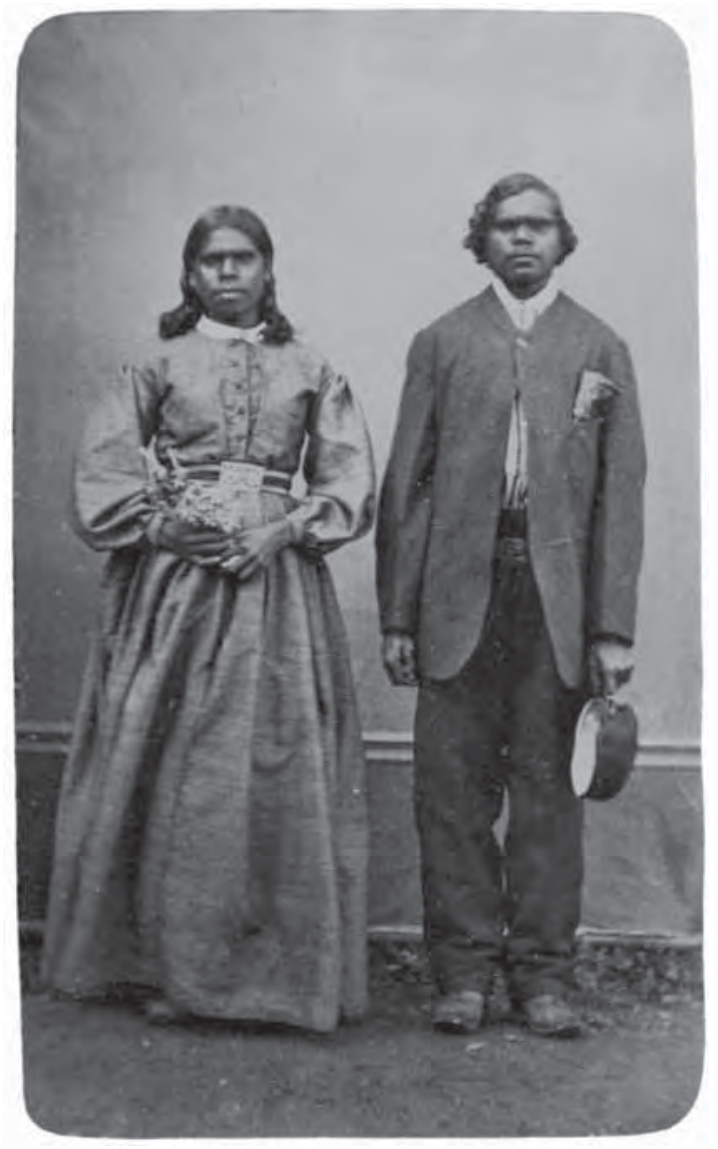


Como é sabido, as relacións de España, e, xa que logo, de Galicia, cos antípodas comezaron, que saibamos, coa chegada dos primeiros navegantes a aquelas terras. No ano de 1519 atópanse mariñeiros galegos nos barcos de Fernando de Magallanes e Juan Sebastián Elcano, na era dos descubrimentos. Entre os anos 1526 e 1527 saíu do porto da Coruña a carabela San Lesmes. Existe información que indica que buques procedentes de Galicia chegaron a ese continente xa no século XVI e que hai comercio coas illas Molucas e territorios adxacentes desde A Coruña, coa concesión dunha casa de contratación especializada en especiería en 1522, denominada Casa do Maluco (Migués, 2008: 85). Pero non é ata o ano de 1606 cando chegaron as expedicións dos navegantes Pedro Fernández de Quirós (1565-1614) e Luis Váez de Torres (1565-1613?), que foron determinantes no descubrimento das terras que hoxe coñecemos como Australia (Fernández de Quirós, 2000, III: 23; Pittarello, 1990; Hervé, 1983). Convén indicar que de Quirós se di que é portugués e non queda claro se o é de nacemento ou de apelido, pero evidentemente estaba ao servizo de Filipe II, rei de Castela, Aragón, Milán, etc., e tamén de Portugal entre os anos 1580 e 1598, e posteriormente do seu fillo e sucesor, Filipe III. Tamén houbo nos séculos XVII e XVIII viaxeiras a Oceanía (Prieto, 1984), entre as que destaca Isabel Barreto de Castro (1567?-1612), muller pontevedresa do navegante Álvaro de Mendaña de Neira, descubridor das illas Salomón e tamén das Marquesas (Bosch, 1943; Elías de Zevallos, 1995). Ela foi a primeira que estivo ao mando dun buque ante o pasamento do seu home e chegou a Manila con Quirós (Majó, 1946; Márquez, 2006). Incidentalmente podemos comentar que se acaba de publicar unha novela de Francisco Núñez Roldán, Jaque al peón (2014), que foi merecente do Premio de Novela Ciudad de Badajoz, e que trata da unión entre España e Portugal sobre a base da correspondencia entre Filipe II desde El Escorial e a Rua do Comércio de Lisboa, na que se asentou Cristóbal de Moura, artífice 
desa unión (Alonso Giráldez, 2014, s. p.). Neste texto pódese apreciar, entre outras moitas cousas, que as identidades neste momento eran transnacionais (Gil, 1989).

Como se ve nesta brevísima viaxe pola historia, xa hai case 500 anos que temos relacións coa Terra Incognita dos antípodas (Fernández-Shaw, 2000: 83-89). Evidentemente o descubrimento de Australia por parte dos navegantes galegos é moi descoñecido e prodúcese 200 anos antes da chegada dos británicos co capitán Cook, que acontece en 1770. Como indica o historiador australiano Kenneth G. McIntyre no título do seu libro The Secret Discovery of Australia ( $\mathrm{O}$ descubrimento secreto de Australia»), os descubrimentos anteriores á chegada dos británicos foron esquecidos. Hai que ter en conta que o primeiro establecemento dos ingleses en Botany Bay, en Sydney, non comezou ata xaneiro de 1788 (Frost, 1980: 27).

Un dos máis ilustres viaxeiros galegos a esta illa que é á vez continente, pero que non tivo unidade política ata o século XX, é Rosendo Salvado, de cuxo nacemento conmemoramos o segundo centenario, e que chegou a Perth en 1846. A figura de Salvado está presente aínda hoxe en Australia, xa que o seu legado de fundación dunha comunidade é unha realidade, pero ademais a súa obra de recoñecemento dos valores culturais e artísticos dos aborixes é coñecida e estase a subliñar e a analizar na actualidade. No período en que Salvado chegou a Australia os colonos trataban os aborixes de tal xeito que se producía unha sorte de escravitude. Neste contexto a visión de Salvado foi basear a vida da súa comunidade en principios de convivencia, creando unha especie de xardín do Edén terrenal no que os propios aborixes puidesen educar os seus conxéneres (Stormon, 1998). Poderiamos dicir que estes mundos decimonónicos son similares aos retratados por Mario Vargas Llosa coa presenza do pintor Paul Gauguin en Tahití na súa novela El paraíso en la otra esquina (2003), pois o ideal de Salvado era o paraíso na terra ou, cando menos, a mellora das condicións en que vivían os aborixes.

Aínda que as relacións entre os viaxeiros procedentes de Galicia e o continente austral viviron moitos altibaixos, seguen vivas e Galicia está presente en Australia a través do ensino da lingua e da literatura galegas en diferentes comunidades e tamén en universidades como as de Queensland, La Trobe, Sydney ou 
Melbourne, onde mesmo existen centros de estudos galegos. Non obstante, o que eu me propoño desenvolver é a idea de que a figura dos galegos en Australia permanece viva no imaxinario colectivo non só polo recordo dos navegantes, polos topónimos, como o estreito de Torres, entre Australia e Papúa Nova Guinea, e polo traballo de Salvado —aínda vivo na florecente comunidade de frades bieitos de Nova Nursia-, senón tamén pola importancia dos elementos galegos na literatura australiana. Boa parte da produción literaria contemporánea de Australia céntrase na exploración dunha nova realidade por parte de personaxes que proveñen de alén do mar, particularmente europeos. Isto sucede na obra de Peter Carey e doutros autores, e tamén sucede que Galicia e os galegos permanecen no imaxinario colectivo e son convertidos en materia literaria e creativa nas artes e na literatura, como acontece cos autores australianos Murray Bail e Sally Morgan, e mesmo co británico Robert Graves. Alternativamente, autores de orixe galega tamén utilizan o tema australiano nos seus textos, tanto se publican en Galicia como se o fan en inglés e son lidos en Australia e nos Estados Unidos.

Un dos casos sobre os que me gustaría chamar hoxe a súa atención é o do navegante portugués Pedro Fernandes de Queirós, que pasa por ser o que lle deu á Terra Australis Incognita o nome de «La Austrialia del Espíritu Santo» para honrar a casa de Austria reinante en España (Clark, 1962, I: 15). Nas viaxes frustradas de Fernandes de Queirós, ou Fernández de Quirós en grafía hispánica e Quiros na anglófona, el imaxinou e proclamou chegar á que denominou a "Gran Terra do Sur», e no imaxinario dos habitantes das terras coas que soñou, isto é, os artistas australianos contemporáneos, foi convertido en personaxe eterno. É probablemente recoñecido por primeira vez polo poeta James McAuley (1917-1976) no poema épico de 1964 titulado Captain Quiros. Neste texto homenaxéase este navegante e os seus soños de heroe ou máis ben antiheroe australiano frustrado, porque non foi quen de realizar o seu soño de facer a terceira viaxe e poñer o pé na illa-continente. Uns anos máis adiante, en 1980, o mellor e máis coñecido compositor musical australiano, Peter Sculthorpe (1929-), dá a coñecer The Visions of Captain Quiros: for guitar and orchestra. Este compositor recoñece a súa fascinación pola épica vinculada á figura de Quirós, ao que chegou a través da obra do poeta James McCauley. O símbolo que representa Pedro 
Fernández de Quirós segue a medrar no imaxinario colectivo dos habitantes de Australia e no ano 1982, para celebrar o 50 aniversario da empresa de comunicación ABC alí, encárgase a produción dunha ópera televisiva titulada Quiros, a cargo do libretista Brian Bell e do propio Peter Sculthorpe. Nesta produción televisiva o noso navegante é representado como un idealista visionario que vai en busca do seu soño, mesmo de maneira teimuda, á vista dos moitos fracasos e obstáculos cos que se atopa. En palabras do historiador K. G. McIntyre, estamos ante o primeiro patriota e o primeiro profeta de Australia (1977: 25). Esta visión idealista do continente que está por descubrir está presente en varias das pasaxes do libreto na voz de Quirós:

I believe in the force that drives us past horizons of the mind... I believe that I could find in these dark seas the Great South Land.

East of India,

West of the Solomons,

South of Java,

A continent.

$A$ vast land from tropic to the pole,

$A$ past and future to unfold,

A last grand enigma to be solved,

This continent.
Creo na forza que nos leva mais aló dos horizontes da mente... Creo que podería atopar nesas escuras augas a Gran Terra do Sur.

Ao leste da India, ao oeste das illas Salomón, ao sur da illa de Xava,

un continente.

Unha vasta terra desde o trópico ao polo, pasado e futuro por desvelar, o derradeiro grande enigma por desentrañar, este continente.

E cando a personaxe de Quirós albisca o fracaso das súas frustradas viaxes analiza os posibles efectos perversos que carrexaría a colonización e contrástaa coa súa vision idealista das viaxes que emprenden os europeos cara a Australia: 
If we had reached the Great South Land,

With all our superstitions,

Our arrogance, our ignorance,

Our covetous ambitions,

We should have spread our decadence,

Our fever and destruction,

And stamped upon that bright new world,

The old world's dark corruption.
Se chegásemos á Gran Terra do Sur,

con todas as nosas supersticións,

a nosa arrogancia, a nosa ignorancia,

as nosas voraces ambicións,

diseminariamos a nosa decadencia,

a nosa febre e destrución,

e estampariamos nese mundo, novo e cheo

de vida,

a escura corrupción do vello.

Así, na ópera non só se reflexiona sobre as viaxes de Quirós e os seus logros ou fracasos, senón que se poñen nos seus beizos consideracións que proveñen dun punto de vista poscolonial, de maneira que con esta perspectiva contemporánea de re-visión da historia de Australia se presentan imaxes máis inclusivas e integradoras. O músico Peter Sculthorpe é coñecido por incluír os traballos dos pintores australianos como inspiración nas súas composicións, en particular as pinturas de Russell Drysdale (1812-1981), e probablemente estas visións dos artistas visuais australianos aparecen incardinadas na composición musical que conmemora a Quirós, e con seguridade na concepción plástica e estética da ópera para a televisión.

A obra de Sculthorpe sobre Quirós foi presentada no 27 de outubro do ano 2007 na sala de concertos da Casa da Ópera de Sydney auspiciada pola Embaixada de España en Australia, e séguese a programar alí, xa que inda no ano 2013 fixo parte do programa de concertos na capital, Camberra. Adicionalmente, o compositor volveu aos temas e á música de Quirós e converteuno nun oratorio titulado The Great South Land («A Gran Terra do Sur»), que foi emitido na ABC Classic FM o sábado 11 de maio de 2013. A conversión da ópera en oratorio permite a súa representación en salas de concertos e sen requirir un gran teatro. Este cambio dá idea de que a obra se transforma para que poida chegar a públicos variados en diferentes lugares do país. Segundo Stephen Adams (2013), a evolución do personaxe de Quirós a través da literatura, da música e da ópera australianas desde os anos 1960 ata a actualidade vai reflectindo as diferentes posicións do país e da intelectualidade en canto á concepción da súa identidade como pobo e á súa propia evolución, afastándose do eurocentrismo e recoñecen- 
do a súa realidade desde posicións que asuman as súas propias complexidades e contradicións históricas (s. p.).

A galega Isabel Barreto, coetánea de Quirós, aparece tamén convertida en personaxe de novela, tanto na cultura española como na anglosaxoa. Da man do xornalista galego Pemón Bouzas entra Isabel Barreto nas letras hispánicas, en El informe Manila: Isabel Barreto, la que surcó los Mares del Sur en busca de las rutas de las especias (2005), e xa uns cincuenta anos antes o crítico literario, poeta e novelista británico Robert Graves (1895-1985), autor de novelas tan memorables como I, Claudius («Eu, Claudio», 1934), tamén convertera en tema novelesco as viaxes de Isabel Barreto en The Islands of Unwisdom (1949), publicada en castelán como Las islas de la imprudencia (1984). Pedro Fernández de Quirós, como piloto principal da frota, é un dos personaxes mellor retratados na novela xunto con Álvaro de Mendaña. Neste relato analízanse as causas dos fracasos futuros dos españois na conquista do océano Pacífico, e da perda de poder no mundo por parte da Coroa española.

Parte da historia da literatura australiana xira arredor da chegada de xentes ao país e a súa particular experiencia exploratoria nel. As exploracións non son necesariamente xeográficas senón tamén psicolóxicas, e, así, atopámonos con novelas de aprendizaxe, coñecidas como Bildungsroman, nas que os personaxes rememoran as súas vivencias na chegada ao país. Un dos novelistas que tratou en detalle esta cuestión é Peter Carey, que aborda a chegada de xentes dos diferentes países do Reino Unido a Australia. En True History of the Kelly Gang (2000) rememora as duras experiencias dunha familia irlandesa que trata de saír da súa pobreza mediante o seu asentamento nos antípodas no século XIX. Tamén neste período sitúa a viaxe de mozos e mozas ingleses que pretenden facer un proxecto vital coa súa chegada a Sydney. Isto sucede en Oscar and Lucinda (1988), na que se presenta unha novela debedora do realismo máxico, que resucita un pasado non moi distante. As perigosas expedicións a través de selvas e xunglas australianas, as antigas descricións de cabalos e carros cruzando ríos, e granxeiros e predicadores colonizando territorios virxes e descoñecidos toman vida tanto na novela de Carey como na versión cinematográfica de Gillian Armstrong (1997). Grazas ao libro e á película baseada nel, podemos volver visitar o século XIX, cunha perspectiva posmoderna e poscolonial encarnada en ambos os dous nun narrador-personaxe, Bob, e recuperar unha imaxe aproxima- 
da das vilas, terreos, misións e portos australianos daquela época (Lorenzo Modia e Alonso Giráldez, 2008: 322). Como nas novelas de García Márquez ou de Salman Rushdie, Oscar and Lucinda parece estar baseada tamén nas moitas posibilidades da casualidade e nas moitas limitacións do destino. Carey utiliza un tipo de narración histórica desde unha perspectiva actual, engadíndolle así un punto de vista avaliativo (Woodcock, 2003: 73) e permitíndonos aprender dos erros do pasado, tanto persoais como colectivos (Lorenzo Modia e Alonso Giráldez, 2008: 327). Carey cuestiona a relatividade das crenzas humanas: móvese entre a ironía e certa mágoa polos seus protagonistas. Oscar semella ir acumulando máis e máis culpa a medida que a película e o libro avanzan. Ao final terá que pagar polos seus erros e pecados. De certa maneira está a pagar tanto polos erros de seu pai como polos seus propios, coma se estivese a reparar o pecado orixinal, o mesmo que lles sucede aos europeos na emigración/colonización de Australia (Lorenzo Modia e Alonso Giráldez, 2008: 328). O desexo de Oscar de atopar unha explicación lóxica á vida resulta ser un fracaso absoluto.

Carey crea claramente a personaxe de Lucinda Leplastrier como unha metáfora de luz fuxidía na vida de sombras de Oscar. Con todo, o seu personaxe está dotado dunha personalidade tan complexa que fai que a súa relación sexa intensa, complicada, potencialmente gratificante aínda que inútil e volátil. É unha herdeira australiana nova que quere dedicar toda a súa enerxía ao traballo no vidro debido ao seu capricho polas pingueiras de vidro do príncipe Rupert. A sociedade de Sydney do século XIX non entende esta empresaria australiana ilusionada co cristal. Ela centra toda a súa enerxía nun soño estético, agora mediatizado polas motivacións relixiosas de Oscar, fundar unha catedral de cristal nos territorios aborixes. Esta empresa, que podería ser esteticamente convincente, non ten sentido nin para o lugar nin para a xente e remata en nada. Deste xeito, o imperialismo critícase indirectamente a través da relixión e dise que, sen dúbida, acabará nun completo fracaso. Neste caso, a violencia úsase como a única maneira de estimular novas crenzas e de borrar as antigas, vellas e dominantes, que comparte a poboación indíxena, e que aínda están «vivas» a través dos espíritos que roldan a terra. Lucinda, malia que se decata de que está namorada, áchase permanentemente illada e sempre hai unha distancia considerable entre ela e Oscar (359). O amor entre eles é menos profundo que a epopea inmersa nos seus soños. En certo xeito, estamos ante unha novela épica, pero a 
realidade é cruel mesmo cos soños épicos se están en contra da xente e da terra (Lorenzo Modia e Alonso Giráldez, 2008: 327). O sentido da terra invade a novela e eles queren evitalo. Lucinda, ao final, adopta un fillo de Oscar e Miriam, que actúa como o emblema do seu amor e soños imposibles, xa que só poden facerse realidade despois da morte. A continuación da historia desta parella é un símbolo da historia actual de Australia. Adoptan unha nova terra para os seus soños e mesmo Lucinda adopta a filla que os seus soños non lle permitiron ter.

As características cinematográficas da novela de Carey chamaron a atención de moitos críticos desde a súa publicación. Polo tanto, a novela chegou ao cinema sen dilación, da man da directora Gillian Armstrong, en 1997 (Craven, 1998: 25-26; Carter, 2006: s. p.). Do mesmo xeito, moitos estudosos viron unha clara similitude entre a obra de Carey e as películas de conquistadores de Werner Herzog Aguirre, Wrath of God («Aguirre ou a ira de Deus») (1972) e Fitzcarraldo (1982) (Woodcock, 1996: 84). De feito, Oscar and Lucinda considérase como o Fitzcarraldo australiano. Referíndose á súa versión cinematográfica da novela, a propia Armstrong admite: «It was my little Fitzcarraldo» [Foi o meu pequeno Fitzcarraldo] (Carter, 2006). A historia de Herzog trata sobre a extravagante figura de Brian Sweeney Fitzgerald, que estaba decidido a conseguir diñeiro para a construción dun palacio da ópera no que el chamaba a vila fronteiriza, na xungla do Perú. A grandiosidade do proxecto é equivalente á súa aparente tolemia. Fitzcarraldo, como lle chamaban, tenta evitar os rápidos do río peruano transportando o barco de vapor por terra, dun río a outro. A película, rodada dun modo magnífico (considérase unha obra mestra), describe esplendidamente a complexidade da tarefa hercúlea que están decididos a levar a cabo. A acción sitúase nun escenario exótico (de feito, a rodaxe resultou un pesadelo). A paisaxe contribúe á creación dunha atmosfera surrealista moi próxima aos parámetros do chamado realismo máxico. Contemplamos a loita entre as forzas humanas e as forzas da natureza, e o resultado é unha película violenta, máxica, asombrosa. Canto a Oscar and Lucinda, no seu filme Gillian Armstrong logra capturar o espírito da historia dun xeito clásico, respectando os símbolos que Peter Carey tanto gusta de utilizar, e tratando o núcleo da historia coa dose de emoción adecuada. En comparación co magnífico Fitzcarraldo, Oscar and Lucin$d a$ tamén tenta recoller as dimensións esenciais da natureza humana, chegando 
ao pouco frecuente equilibrio entre a razón e a tolemia. Oscar trata de levar a súa catedral de cristal ao interior do continente austral. Neste sentido parece estar baseada na aventura de Rosendo Salvado tratando de levar o seu piano e os materiais para construír o mosteiro, no século XIX, polo medio do bush australiano co fin de que os e as aborixes tivesen unha mellor vida espiritual e material.

Tamén pareceu pertinente mencionar aquí dúas novelas de autores australianos contemporáneos nas que son moi relevantes os topónimos galegos. Trátase de Eucalyptus (1998), de Murray Bail, e My Place ("O sitio de onde son») (1987), de Sally Morgan. Na primeira novela o nome Corunna, que é a forma inglesa da cidade da Coruña, evoca un lugar distante con lendas e misterios. $\mathrm{Na}$ novela refírese a historia dunha australiana que se namora dun estranxeiro escuro e na que ambos se atopan diante dun espello milagroso que hai no faro da Coruña:

There's a place called Corunna in north-west Spain, he had said. A place of rocks geological delirium. Corunna is known for just two things: foul weather, it never stops raining, and its lighthouse built of granite in the Dark Ages. Local families call it 'the Tower of Caramel'. [Hai un lugar chamado A Coruña no noroeste de España, dixera el. Un lugar rochoso, un delirio xeolóxico. A Coruña só se coñece por dúas cousas: o mal tempo, nunca para de chover, e o seu faro, feito de granito na Idade Escura. As familias da zona chámanlle «a Torre de Caramelo»]. (208)

O relato sobre A Coruña aparece como especular xa que se crea nos antípodas unha historia que reflicte a que sucede nesta cidade galega, onde chega a namorada buscando o seu amante, que xa non pode atopar (Cabarcos, 2008: 265). Prodúcese, polo tanto, unha relación especular entre o que lle ocorre á protagonista da novela en Australia e o que lle pasa á personaxe imaxinaria na que ela pensa e que vén á Coruña. Estes paralelismos están iluminados polos espellos que historicamente se usaban na Torre de Hércules pare darlle maior proxección á luz do faro, que parece de caramelo debido á cor do granito da súa fachada. Ellen tamén se encontra atrapada nunha torre metafórica á espera do seu amante. Nos reflexos hai sempre unha imaxe ao dereito e unha ao revés, e nesta ocasión é a muller da Coruña a que non atopa ao seu amado para que na imaxe inversa Ellen poida ser feliz co seu. 
No caso de My Place, de Sally Morgan, o topónimo Corunna aparece como nome de lugar en «Return to Corunna» e como antropónimo ou apelido familiar en tres seccións que levan un título independente, denominadas «Arthur Corunna’s Story» («A historia de Arturo Coruña)), «Gladys Corunna’s Story» («A historia de Gladys Coruña) e «Daisy Corunna’s Story» («A historia de Daisy Coruña). Estes nomes proveñen do topónimo australiano Corunna Downs, situado en Australia Occidental, xa que un antepasado da protagonista procede dun rancho de alí:

Corunna Downs was named by my husband. There is a poem, «Corunna». He was reading a book at the time with the natives, and in it was a poem about Corunna, I think it was in Spain, so he named the station after that. [O meu home chamoulle Corunna Downs. Hai un poema, «Corunna». El estaba a ler un libro nesa época cos nativos e nel contínase un poema sobre A Coruña, creo que estaba en España, e púxolle o nome ao rancho polo poema]. (Morgan, 2003: 168)

O poema máis coñecido sobre a cidade no canon anglosaxón é o creado polo escritor irlandés Charles Wolfe sobre a batalla de Elviña, coñecida no Reino Unido como batalla da Coruña, que aconteceu en xaneiro de 1809. Trátase da loita en España entre os franceses e os ingleses pola preeminencia en Europa e no mundo, denominada en Inglaterra Peninsular War e que no noso país é coñecida como guerra da Independencia. Os ingleses considerábanse inferiores en forzas e decidiron evitar a confrontación coas tropas napoleónicas e retirarse por mar a través do porto da Coruña. A estratexia tivo éxito pero o propio xeneral británico ao mando, sir John Moore, morreu na loita nos outeiros de Elviña, situados á entrada da cidade da Coruña, hoxe campus universitario de Elviña. O poema «On the Burial of Sir John Moore after Corunna» («Sobre o enterro de sir John Moore tras A Coruña»), que Wolfe publicou por primeira vez na revista The Newry Telegraph en 1817 e posteriormente, de maneira anónima, na escocesa Blackwood's Magazine, chamou a atención de lectores ilustres como lord Byron, Edgar Allan Poe ou George Orwell e de antólogos varios que continuaron a diseminalo hasta que chegou a ser a elexía patriótica máis difundida no Imperio británico (Cabarcos, 2008: 269), e que fai parte obrigatoria da educación de todos os escolares anglosaxóns. Mesmo a escritora galega Rosalía 
de Castro quixo participar dese dó literario e publicou un poema titulado «Na tomba do xeneral Sir John Moore». Neste contexto a loita de poderes que se estableceu en Europa ao principio do século XIX a través desta cidade galega é representada na narrativa australiana cunha significación diferente, xa que o poder colonial toma posesión de novos territorios, nos que se inclúen os aborixes —que pasan a servir os británicos e mesmo a ser da súa propiedade—, que son chamados cos nomes e apelidos que lles poñen os amos, que evitan así recoñecer a súa propia identidade, orixe e cultura. Como di Nan referíndose aos aborixes dos ranchos no século XIX, isto é, no tempo de Salvado, «in those days, we was owned, like a cow or a horse» [naqueles tempos, nós eramos propiedades, como unha vaca ou un cabalo] (Morgan, 2003: 337, cit. en Cabarcos, 2008: 274). É dicir, non tiñan entidade humana senón como animais de traballo. O nome Coruña, que na metrópole se asociaba co lugar de liberación do xugo napoleónico en España e o primeiro paso para a derrota final, pasa a ter na novela de Sally Morgan significados varios dependendo de se o pronunciaban os propietarios ou os aborixes. No caso das mulleres esta submisión é dobre, xa que sofren tamén explotación sexual por parte do amo do rancho. Despois dunha relación sexual con Annie nace Nan, que pasa a ser persoal do predio e con quen o amo ten unha relación incestuosa que produce novos traballadores para a plantación (Cabarcos, 2008: 274). Andando o tempo, a vella facenda denominada «Coruña» convértese en base aérea para as forzas australianas na Segunda Guerra Mundial e adquire de novo unha significación de lugar de liberación do xugo das tropas do Eixe, e incluso recibe posteriormente un recoñecemento polo desenvolvemento dos labores agrícolas no noroeste australiano.

Como vemos, a relación de Galicia con Australia perdura nos topónimos, ben levados por galegos ou por viaxeiros que os mantiñan de maneira simbólica na súa iconografía. A complexidade da significación multiplícase en Australia, e ponse de manifesto dependendo do período en que se analicen e do punto de vista desde o que se faga.

Existen outros elementos da cultura de Galicia que persisten na actualidade na cultura e literatura australianas. Trátase dos galegos que emigraron a ese país nas grandes migracións marítimas dos anos cincuenta e sesenta desde aquí ou desde outros países onde recalaran con anterioridade, tales como Brasil, Francia ou Inglaterra, entre outros. Os galegos e os españois chegaron en vapores freta- 
dos polo Goberno australiano en programas coñecidos como «Canguro», «Eucaliptus», «Emu», «Kerry». Tamén chegaron continxentes de aproximadamente 500 mulleres solteiras nun programa denominado "Marta», recrutadas en colaboración coa Igrexa española para acompañar no país austral os máis de 7000 homes que emigraron daquela (Boland, 2008: 16). Moitos encontraron en Australia o mellor futuro ao que aspiraban, e especialmente os seus fillos, aínda que para outros non o foi tanto.

Algúns destes emigrantes están publicando en inglés textos en que utilizan Galicia como tema. Un destes autores é Félix Calviño, ou Calvino, como é coñecido nos antípodas, que foi nado en Galicia no ano 1944. Este autor reflicte as memorias da súa infancia en Galicia e expón na súa literatura as dificultades da emigración desde o punto de vista dun galego, convertendo as vidas de tantas xentes en literatura que poida ser compartida por lectores de diferentes continentes. Un dos seus textos é unha colección de relatos, A Hatful of Cherries: Short Stories («Un pucho de cereixas: Relatos»), que foi publicada no ano 2007 e reeditada en 2011. Xa desde o comezo tivo un grande éxito. Eses dezaseis relatos son os dun autor que iconicamente procede doutra parte. Parece irónico que o nome da súa aldea natal sexa precisamente Alemparte, en Lalín, pero que domine a lingua inglesa e que decidise dedicarse á literatura na madurez deixando a súa florecente carreira como empresario en Australia. Roy Boland, da University of Sydney, indica que publicou nas revistas máis prestixiosas dos antípodas, como Quadrant, nas que colaboran autores do talle de Peter Carey ou David Malouf (Alonso, 2008: s. p). O seu uso da lingua inglesa é excepcional, pero desa mestura do galego - particularmente nos temas de «Don't Touch Anything» («Non toques a nada»), «Detour» («O desvío») ou «Basilio»— e do alleo da lingua e cultura australianas saen textos dunha beleza estraña que lle confiren moito atractivo. Segundo o profesor Boland, Félix Calviño decide usar temas galegos e escribir como os autores anglosaxóns, e desa mestura sae a súa orixinalidade. Como el mesmo indica no prefacio ao seu libro de relatos, deixou Galicia para non ter que facer o servizo militar obrigatorio no franquismo. $\mathrm{O}$ autor declarou nunha entrevista que a escrita lle permitiu deprender moito e profundar nas conexións entre a memoria e a imaxinación. Trata temas como a infancia, a dureza da posguerra en Galicia, pero tamén sucesos aparentemente sen importancia acaecidos nas rúas das cidades australianas e que translocen un suspense, 
un azar ou unha traxedia profunda. Os diferentes lugares onde acontecen as historias non fan o libro inconexo, senón que resulta arquetípico da esencia australiana, historicamente composta por emigrantes. Os contos están cheos de tenrura, humor e ironía nos temas cotiáns, cun estilo sinxelo e claro, como acontece coa frase seguinte: "Grandfather had become disillusioned with women when my Grandmother died young and without his consent» (Calvino, 2007: 42) [O avó desencantouse das mulleres cando a avoa morreu nova e sen permiso del].

Cando dicimos éxito non nos anima o lexítimo orgullo de galegos a magnificar a obra dun compatriota, senón que vén avalado pola voz dun dos grandes autores da literatura australiana, David Malouf (1934-), dramaturgo e poeta, pero coñecido especialmente polas súas novelas Fly Away Peter (1982) e Remembering Babylon (1993). Sobre a colección de contos de Félix Calviño Malouf dixo:

Trátase de testemuños doutras vidas noutro lugar, algo moi vivo, emocionante, humorístico, estraño, un regalo para o lector, como tamén o é o xeito austero e tenro en que está escrito. Calviño é unha voz nova neste panorama, unha voz fascinante, individual, e, agora que nos demos conta de que existe, resulta que é indispensable para todos os que constrúen a nosa historia.

Esta afirmación de Malouf sobre un libro de relatos de tema galego como coadxuvante á construción da historia de Australia, e o que lle achegaron a esta os inmigrantes, está relacionada coa esencia do país mesmo, construído desde a periferia e por inmigrantes de toda clase. Australia é un país aínda inexplorado, no que a meirande parte da poboación se sitúa na periferia, mirando cara ao océano e parcialmente de costas á daquela terra ignota. É por iso polo que se conforma cunha boa parte de emigrantes que aínda senten que están a explorar o territorio. Neste contexto os escritores contemporáneos teñen a percepción de que Australia non é de momento un país, porque non falan desde dentro senón desde a periferia, en palabras da poeta e conservacionista Judith Wright (1915-2000); esta idea foi plasmada así: «Australia is still, for us, not a country but a state of mind. We do not yet speak from within her, but from the outside» [Para nós, Australia non é de momento un país, senón un estado mental. Aínda non 
falamos desde ela, senón desde fóra] (1969: 301). Polo tanto, se entendemos que a realidade no imaxinario colectivo australiano é a dunha comunidade imaxinada a partir de xentes de moitas orixes diferentes (Anderson, 1983: 6-7), comprenderemos a afirmación de Malouf de que os textos dun autor de orixe galega e que falan de realidades galegas contribúen á construción da historia de Australia. Neste senso a periferia e as marxes confórmanse como un lugar de creación e de poder e convértense en centrais na historia contemporánea da literatura australiana (Hooks, 1990: 152).

O escritor australiano Venero Armanno (1959-) dixo na presentación deste libro de contos que no estilo de Calviño non hai romanticismos, ten un estilo moi natural. Tamén aseverou que non cre que estea lonxe de Giuseppe Tomasi di Lampedusa, de Italo Svevo, de Italo Calvino (pero non son parentes!) ou do seu favorito, Cesare Pavese, engadiu.

Un dos contos de Félix Calviño foi adaptado para o cine nunha curta titulada Unfinished Thoughts («Pensamentos sen rematar»). Tivo un gran recoñecemento en Australia, xa que estivo nomeada para oito premios de cine de Australia Meridional (South Australia Screen Awards) e conseguiu o de mellor actriz, para Chantal Contouri. Cando vemos a película, aínda que ten un director de orixe grega, Dimitrios Pouliotis, e ambienta o filme na cultura dese país, podemos ver a Galicia da emigración sen dúbida ningunha.

Félix Calviño presentou en xaneiro de 2014 unha novella titulada Alfonso, que de novo contou co escritor David Malouf na presentación, realizada o 20 de febreiro de 2014 en Sydney. O escritor de orixe italiana Venero Armanno, sobre esta nova novela breve, afirmou:

Alfonso is a gentle yet searching exploration of a Spanish migrant's feelings and experiences in the country Australia used to be more than forty years ago. Felix Calvino infuses the stuff of everyday life with tenderness and magic. He recovers a lost time and sensibility. The past shimmers back to life. [Alfonso é unha exploración profunda e delicada a un tempo dos sentimentos e experiencias dun emigrante no país que era Australia hai máis de corenta anos. Félix Calviño inocula tenrura e maxia aos temas da vida cotiá e recupera a sensibilidade dun tempo perdido. O pasado reloce de volta á vida]. 
Tamén se indica na presentación do libro que nesta experiencia de emigración se entrega todo a cambio da seguridade material. Nunha entrevista o autor fala das súas cinco influencias literarias fundamentais: trátase de Cervantes, Flaubert, Chekhov, Hemingway e García Márquez (Horner, 2009: s. p.).

Para concluír, tratei de mostrar que os viaxeiros de aquí están presentes en poemas, óperas, composicións musicais e novelas, como é o caso do navegante Quirós, e aparecen mencionados en estudos como o titulado «Imagining Australia» (Adams, 2013), co que están contribuíndo á construción da identidade australiana contemporánea. Tamén sucede con novelas de xentes procedentes das Illas Británicas, como acontece no caso de Peter Carey, que publica novelas a finais do século XX nas que se trata sobre a construción e explotación e exploración do país no século XIX por parte de británicos chegados a Sydney. Sally Morgan e Murray Bail utilizan o nome da cidade da Coruña con significacións diferentes: as que poderían ter, en primeiro lugar, para os habitantes desta cidade galega; en segundo lugar, para os británicos que o recordaron ao darlle este nome a unha zona de Australia; e, en terceiro lugar, para os australianos que viviron nela segundo as épocas e as vidas que levasen, e segundo fosen amos ou aborixes. A materia de Galicia tamén aparece noutros escritores australianos contemporáneos, como é o caso de Félix Calviño, co que a cultura rural da Galicia posterior á Guerra Civil entra a formar parte do imaxinario colectivo das orixes multiétnicas da Australia actual e está entrando a formar parte do canon literario en Australia da man nada menos que de escritores como David Malouf. Polo tanto, na conformación do que cremos que é un país entran a facer parte dela as imaxes que del temos, nos mapas, nos periódicos e nas súas manifestacións artísticas, e así consideramos que Galicia é parte constitutiva da literatura e cultura australianas contemporáneas. 


\section{REFERENCIAS BIBLIOGRÁFICAS}

ADAMS, Stephen (2013): «Imagining Australia», Australian Music, 7 de maio de 2013 (http://www.abc.net. $\mathrm{au} /$ classic/content/2013/05/07/3753891.htm).

AGUIRRE, Wrath of God (dir. Werner Herzog, int. Klaus Kinski, Helena Rojo, Ruy Guerra, Peter Berling), Hessischer Rundfrunk, 1972.

Alonso Giráldez, José Miguel (2008): «Félix Calviño publica en inglés un libro de relatos galaicos en Australia», El Correo Gallego, 18 de maio.

Alonso Giráldez, José Miguel (2014): «El sábado libro: Felix Calviño, escritor gallego en lengua inglesa», El Correo Gallego, 24 de maio (http://www.elcorreogallego.es/tendencias/ecg/felix-calvino-escritor-gallego-lengua-inglesa/idEdicion-2014-05-24/idNoticia-870620/\#).

ANDERSON, Benedict (1983): Imagined Communities: Reflections on the Origin and Spread of Nationalism, London, Verso.

ANDERSON IMBERT, Enrique (1976 [1992]): El realismo mágico y otros ensayos, Caracas, Monte Ávila.

ARCHER-LeAn, Clare (2007): «Review - Social Alternatives» [recensión de A Hatful of Cherries], Social Alternatives, 26:4 (http://ahatfulofcherries.blogspot.com.es/2008/11/review_11.html).

BaIL, Murray (1998 [1999]): Eucalyptus, London, Harvill Press.

Boland Osegueda, Roy C. (2008): «The Search for Paradise. Reflections on Historical and Cultural Relations between Spain, Galicia and Australia», en María Jesús Lorenzo Modia / Roy C. Boland Osegueda (eds.), Australia and Galicia: Defeating the Tyranny of Distance = Australia e Galicia: Vencendo a tirania do afastamento, Sydney, Antípodas Monographs, 9-20.

Bosch Barrett, Manuel (1943): Doña Isabel Barreto: Adelantada de las islas Salomón, Barcelona, Juventud. BouZas, Pemón (2005): El informe Manila, Barcelona, Martínez Roca.

Cabarcos Traseira, María Jesús (2008): «Heroes and Mirrors: The Presence of Corunna in Murray Bail's Eucalyptus and Sally Morgan's My Place», en María Jesús Lorenzo Modia / Roy C. Boland Osegueda (eds.), Australia and Galicia: Defeating the Tyranny of Distance = Australia e Galicia: Vencendo a tirania do afastamento, Sydney, Antípodas Monographs, 257-274.

Calvino, Félix (2007): A Hatful of Cherries: Short Stories, Kew, VIC, Arcadia (an imprint of Australian Scholarly Publishing).

Calvino, Félix (2009): "They Are Only Dreams», The Barcelona Review, e en K. Scott Forman / Kona Morris / Nancy Stohlman (eds.), Fast Forward, Vol. 2, FF >> Press.

Calvino, Félix (2013): Alfonso, Sydney, Arcadia.

CAREY, Peter (1988): Oscar and Lucinda, Brisbane, The University of Queensland Press.

CAREY, Peter (2000 [2002]): True History of the Kelly Gang, London, Faber.

CARTER, Helen (2006): «Gillian Armstrong», Senses of Cinema, 15 de setembro (http://www.sensesofcinema.com/contents/directors/02/armstrong.html\#16).

ClarK, Manning (1962-1987): A History of Australia, Melbourne, Melbourne University Press, 6 vols.

Craven, Peter (1998): «Review of the film Oscar and Lucinda», Australian Book Review, 198: 25-26.

Edgar Allan Poe Society of Baltimore, Inc. (1999/2007): «Poe's Criticisms», The Works of Edgar Allan Poe, EE. UU., 20 de agosto de 1999 (http://www.eapoe.org/works/criticsm/wolfe.htm) [última consulta: 20 de outubro de 2007].

Elías de Zevallos, Hilda (1995): El entorno de Isabel Barreto Castro de Mendaña y su viaje hacia las Islas Salomón, Lima, Asociación Nacional Pro-Marina del Perú. 
FERnÁndez De Quirós, Pedro (2000): Descubrimiento de las regiones austriales (ed. Roberto Ferrando Pérez), Madrid, Dastin Historia.

FERnÁndez-SHAW, Carlos M. (2000): España y Australia: Cinco siglos de historia = Spain and Australia: Five Hundred Years of Relations (ed. Mercedes Palau e Alonso Ibarrola), Madrid, Dirección General de Relaciones Culturales y Científicas, Ministerio de Asuntos Exteriores de España, 83-89.

FitzCARRALDO (dir. e prod. Werner Herzog, int. Klaus Kinski, Claudia Cardinale, Paul Hittscher, Miguel Ángel Fuentes, José Lewgoy), Alemaña Occidental, 1982.

Frost, Alan (1980): Convicts and Empire: A Naval Question (1776-1811), Melbourne, OUP.

GarCía MárqueZ, Gabriel (1967 [2007]): Cien años de soledad [edición conmemorativa], Madrid, Real Academia Española / Asociación de Academias de la Lengua Española / Alfaguara. [Trad. Gregory Rabassa (1970): One Hundred Years of Solitude, New York, Harper and Row].

GIL, Juan (1989 [1992]): Mitos y utopías del Descubrimiento: El Pacífico, Madrid, Alianza Universidad, 3 vols.

Graves, Robert (1949): The Islands of Unwisdom, London, Carcanet (rpt. 2003, New York, Doubleday). Graves, Robert (1984): Las islas de la imprudencia, Barcelona, Edhasa (trad. Rubén Masera).

Hervé, Roger (1983): Chance Discovery of Australia and New Zealand by Portuguese and Spanish Navigators between 1521 and 1528, Palmerston North, The Dunmore Press.

Hooks, Bell (1990): Yearning: Race, Gender and Cultural Politics, Boston, Massachusetts, South End Press. Horner, Anna (2009): «Félix Calvino, author of A Hatful of Cherries, makes U.S. debut», Baltimore Literature Examiner, 30 de xullo (http://www.examiner.com/article/f-lix-calvino-author-of-a-hatful-of-cherries-makes-u-s-debut).

Lorenzo Modia, María Jesús / Alonso Giráldez, José Miguel (2008): «Misfits in the Hands of Destiny: Peter Carey's Antipodean Conquest in Oscar and Lucinda», en María Jesús Lorenzo Modia / Roy C. Boland Osegueda (eds.), Australia and Galicia: Defeating the Tyranny of Distance = Australia e Galicia: Vencendo a tiranía do afastamento, Sydney, Antípodas Monographs, 321-336.

Majó Framis, Ricardo (1946): Navegantes y conquistadores españoles del siglo XVI, Madrid, Aguilar.

Márquez de la Plata, Vicenta María (2006): Mujeres de acción en el Siglo de Oro, Madrid, Castalia.

McAuley, James (1964): Captain Quiros, Sydney, Angus \& Robertson.

MCInTyre, Kenneth Gordon (1977): The Secret Discovery of Australia: Portuguese Ventures 200 Years Before Captain Cook, London, Souvenir Press.

Migués RodrígueZ, Vítor Manuel (2008): «Early Links Between Galicia and the Pacific: The House of the Maluccas in Corunna», en María Jesús Lorenzo Modia / Roy C. Boland Osegueda (eds.), Australia and Galicia: Defeating the Tyranny of Distance = Australia e Galicia: Vencendo a tirania do afastamento, Sydney, Antípodas Monographs, 85-100.

Morgan, Sally (1987 [2003]): My Place, London, Virago Press.

NúNÉE RoldÁn, Francisco (2014): Jaque al peón, Sevilla, Algaida.

Orwell, George (2008): «The Lion and the Unicorn», Charles' George Orwell Links (http://www.netcharles.com/orwell/essays/lion-andunicorn1.htm) [última consulta: 5 de setembro de 2007].

OSCAR and Lucinda (dir. Gillian Armstrong, int. Ralph Fiennes, Cate Blanchett, baseada na novela homónima de Peter Carey) [CD-ROM], Estados Unidos / Australia / Reino Unido, Twentieth Century Fox, 1997.

Pittarello, Elide (ed. e intr.) (1990): Pedro Fernández de Quirós: Viaje a las islas Salomón (1595-1596), Roma, Consiglio Nazionale delle Ricerche / Bulzoni Editore. 
PoE, Edgar Allan (ca. 1825): nota non publicada de «The Burial of Sir John Moore», reimp. «Notice of "The Burial of Sir John Moore"», 20 de agosto de 1999, EE. UU., Edgar Allan Poe Society of Baltimore, Inc. (http://www.eapoe.org/works/criticsm/wolfe.htm) [última consulta: 20 de outubro de 2007].

Portsmouth NAPOlEONiC SOCIETy (1999): «The Battle for Elvina», Portsmouth, setembro (http://www. pns1814.co.uk/corunna.htm) [última consulta: 20 de outubro de 2007].

PRIETO, Carlos (1984): El Océano Pacífico: Navegantes españoles del siglo XVI, Madrid, Alianza Editorial.

SCUlthorpe, Peter (1980): The Visions of Captain Quiros: for guitar and orchestra, London, Faber.

SCULThORPE, Peter (2013): The Great South Land, ABC Classic FM, sábado 11 de maio.

SCULThorpe, Peter / BeLl, Brian (1982): Quiros [filme da ABC TV].

Stormon, Edward J. (1998): The Salvado Memoirs, Nedlands, University of Western Australia.

VARGAS LLOSA, Mario (2003): El paraíso en la otra esquina, Barcelona, Alfaguara.

Woodcock, Bruce (1996): Peter Carey, Manchester, Manchester UP (2nd ed. 2003).

Wolfe, Charles (1979): "The Burial of Sir John Moore after Corunna», en Helen Gardner (ed.), The Oxford Book of English Verse: 1250-1950, Oxford, Oxford University Press, 579-580.

Wright, Judith (1969): "The Upside-Down Hut», en John Barnes (ed.), The Writer in Australia, Melbourne, Oxford UP.

ZARAGOZA, Justo (1876-1882): Historia del descubrimiento de las regiones austriales hecho por el general Pedro Fernández de Quirós, Madrid, Impr. de Manuel G. Hernández, 3 vols. 